\title{
APLIKASI SISTEM INFORMASI PEMANTAUAN INVENTORY STOCK OPNAME BERBASIS WEB PADA PT MAKMUR BERKAT SOLUSI LOGISTIC
}

\author{
Sugeng Santoso ${ }^{1}$, Ilamsyah $^{2}$, Winda Novita ${ }^{*^{3}}$ \\ ${ }^{1}$ Program Studi Teknik Informatika Fakultas Sains dan Teknologi Universitas Raharja \\ ${ }^{2}$ Program Studi Sistem Komputer Fakultas Sains dan Teknologi Universitas Raharja \\ ${ }^{3}$ Program Studi Sistem Informasi Fakultas Sains dan Teknologi Universitas Raharja \\ Email: ${ }^{1}$ sugeng.santoso@ raharja.info, ${ }^{2}$ ilamsyah@ $\underline{\text { raharja.info, }},{ }^{* 3}$ winda_novita@ raharja.info
}

\begin{abstract}
Abstrak
Sistem ini bertujuan untuk merancang aplikasi sistem inventory barang yang dapat membantu dalam melakukan pengecekan laporan stock pada PT Makmur Berkat Solusi Logistic.karena memiliki beberapa kendala dalam menggunakan sistem yang sudah ada yaitu informasi tidak update dan keterlambatan laporan sehingga pemilik barang tidak dapat melakukan pengecekan laporan stock apabila terjadi nya barang masuk dan keluar secara terupdate untuk itu memerlukan sistem yang dapat membantu dalam pembuatan laporan stock barang agar bisa di pantau oleh pemilik barang dan agar dapat mencegah terjadi nya over load atau kelebihan persedian di dalam gudang.Metode analisis data yang digunakan adalah analisis value chain dan PIECES dengan Analisis tersebut dilakukan dengan cara berbagai data yang berhasil dikumpulkan perisetdilapangan dimana data yang dikumpulkan, disusun dan diinterpresentasikan, serta dianalisa, sehinggamemberikan keterangan yang lengkap bagi pemecahan masalah. Prosedur sistem yang berjalan menggunakan UML (Unified Modeling Language)dan metode perancangan menggunakan XAMPP,PHP,MySql.dari penelitian ini akan diketahui bagaimana metode yang cocok agar sistem dapat dikembaangkan lagi untuk mempermudah laporan stock pemantauan Selain itu dihasilkan pula perancangan sistem persediaan laporan stock yang diharapkan dapat menampilkan laporan yangaktual dan mudah dipahami.
\end{abstract}

Kata kunci -Laporan, stock, Pemantauan,berbasis web

\begin{abstract}
This system aims to design an inventory system application that can assist in checking stock reports at PT Makmur Berkat Solusi Logistik. Because it has several obstacles in using the existing system, namely information that does not update and report delay so that the owner of the goods cannot check stock reports if there is an update in and out of goods, it requires a system that can assist in making stock reports so that goods can be monitored by the owner of the goods and in order to prevent over load or excess inventory in the warehouse. Data analysis method used is analysis value chain and PIECES with the analysis carried out by means of the various data collected by researchers in the field where data collected, compiled and interpreted, and analyzed, so as to provide complete information for problem solving. System procedures that run using UML (Unified Modeling Language) and design methods using XАMPP, PHP, MySql. From this study, it will be known how the method is suitable so that the system can be developed again to simplify stock monitoring reports. expected to display actual and easy-to-understand reports.
\end{abstract}

Keyword-Reports, stock, monitoring, web-based 


\section{PENDAHULUAN}

PT Berkat Makmur Solusi merupakan perusahaan yang bergerak dibidang jasa Supply Chain \& Logistic Services,PT Makmur Berkat Solusi hadir menjadi partner bisnis untuk mengembangkan usaha dalam pengelolahan sistem penyimpanan barang yang aman dan profesional untuk menjadi salah satu yang terbaik dalam bisnis pergudangan, dengan secara konsisten memberikan pelayanan secara konsisten tinggi dan inovatif yang didukung oleh sumber daya yang terbaik dengan biaya yang bersaing berusaha untuk membangun hubungan yang saling menguntungkan dengan pelanggan untuk terus meningkatkan pelayanan guna memenuhi kebutuhan mereka. Dalam proses penyewahan gudang untuk barang seperti biji plastic yang dibedah kan berdasarkan batch number dan Type product.Sistem pengiriman Stock yang berjalan saat ini masih Offline dan menggunakan Microsoft excel dan sistem terkumputerisasi masih kurang efektif dan efesien untuk melihat stok yang dikirim ke custumer masih menggunakan email.

Saat ini masih memiliki kekurangan dan kelemahan seperti memerlukan waktu yang cukup lama untuk mengetahui jumlah persedian stok barang karena custumer ingin selalu up date dalam jumlah stok yang sekarang tersedia sedangkan pihak admin membutuhkan waktu yang lama untuk membuat laporan permintaan pengeluaran barang apa bila semua kegiatan di dalam gudang sudah,selesai perhari baru stok di kirim ke custumer,sehingga menyebabkan kinerja perusahaan menjadi terhambat dalam penginputan data untuk langsung sampai ke pihak custumer.

\section{PERMASALAHAN}

Sistem yang berjalan saat ini masih menggunakan Ms excel untuk laporan stock dan masih menggunakan email untuk laporan stock apabila semua kegiatan di dalam gudang selesai baru laporan stock di kirim ke customer untuk dibutuhkan sistem yang dapat.Untuk mempermudah dan,membantu meningkatkan Pengelolaan barang, terutama mengenai jenis barang, penginputan data keluar masuk barang, pembuatan laporannya agar bisa lebih mudah dan efektif Untuk mempercepat dan mempermudah pekerjaan administrasi, baik dalam proses penginputan data maupun pembuatan laporan Sistem sebagai penyimpanan data secara komputerisasi sehingga mudah untuk di update.

\section{TUJUAN}

Untuk merancang sistem pemantauan stock yang dapat dibutuhkan perusahaan dalam melakukan kegiatan Inbound dan Outbound dan pengiriman stock secara cepat dan efektif untuk dapat membantu dalam proses perkerjaan yang dilakukan.

\section{MANFAAT}

2. Merancang sistem informasi yang dapat membantu perusahaan dalam pembuatan laporan yang dapat digunakan dengan lebih baik dan efektif bagi perusahaan.

3. Terciptanya kepuasan batin ketika menghasilkan solusi atau suatu karya yang dapat membantu suatu organisasi.

\section{TINJAUAN PUSTAKA}

\section{Definisi Perancangan}

Menurut Santoso dalam jurnal teknologi informasi mura (2017:100),perancangan sistem adalah tahap yang dilakukan setalah melakukan analisis sistem,pendefinisian kebutuhan-kebutuhan sistem yang akan dibangun ,dan persiapan untuk merancang bangun implemantasi sistem dimulai dengan memahami sistem yang sedang berjalan dan kriteria-kriteria sistem yang akan dibangun biasanya menggunakan pemodelan secara terstruktur yang di gambarkan oleh grafik atau diagram. 


\section{Definisi Sistem}

Menurut Sutarman yang dikutif oleh Noor dkk dalam jurnal sains dan Informasi (2016:68),pengertian sistem adalah kumpulan elemen yang saling berhubungan dan saling berinteraksi dalam satu kesatuan untuk menjalankan suatu proses pencapaian suatu tujuan utama Informasi

Menurut Muhammad Muslihudin dan Oktafianto yang dikutif oleh nugraha dkk dalam jurnal manajemen informasi (2017:4)"informasi merupakan data yang diolah menjadi bentuk yang berguna untuk membuat keputusan"

\section{Definisi Pemantauan}

Menurut Eman Suherman,(2015)"pemantauan adalah suatu kegiatan untuk mengikuti perkembangan suatu program yang dilakukan secara mantap dan teratur serta secara terus menerus."

\section{Definisi Inventory}

Menurut Rosyidhana (2014 : 1),'Inventory adalah sejumlah barang yang disediakan untuk memenuhi permintaan dari pelanggan".

\section{Definisi UML}

Menurut Roger s.pressman,ph.d yang dikutif oleh hadi dkk dalam jurnal teknologi (2017:142),Unified modeling language (UML) adalah Bahasa standar untuk penulisan cetak biri perangkat lunak.UML dapat digunakan untuk memvisualisasikan ,menentukan,mengonstruksi,dan mendokumentasikan artifak-artifak suatu sistem softwareintensive.dengan kata lain,sama seperti arsitek bangunan membuat cetak biru untuk digunakanoleh perusahaan konstruksi,Arsitek perangkat lunak membuat diagram UML untuk membuat pengembangan perangkat lunak dalam membuat perangkat lunak.

\section{METODE PENELITIAN}

Metode pengumpulan data yang digunakan oleh penulis dan pembuatan laporan menggunakan metode sebagai berikut :

1. Metode Observasi (Pengamatan Langsung)

Tempat observasi penelitian ini berada di PT Makmur Berkat Solusi logistic yang beralamat di pergudangan sentra kosambi.

2. Metode Studi Pustaka

Dalam pengumpulan studi pustaka dari beberapa sumber Literature Seperti:Bukti, Jurnal, Makalah, Internet dan lain sebagai-nya yang Berkaitan dengan Penelitian Sebagai, Bahan Referensi dalam Penyusunan laporan ini.

3. Metode Wawancara

Pada metode ini penulis melakukan pengumpulan data dengan cara Tanya-jawab atau wawancara yang dilakukan secara langsung kepada pihak yang terkait pada PT Berkat Makmur solusi logistic

\section{METODE ANALISA}

Setelah proses pengumpulan data dilakukan melalui beberapa metode,maka data sudah Pakan diolah dan dianalisa supaya mendapat hasil akhir yang bermanfaat pada penelitian ini.peneliti menggunakan metode analisa value chain yang digunakan untuk menganalisa sistem yang berjalan untuk dapat mengidentifikasi konsep bisnis dengan cara menganalisa langkahlangkah apa saja yang harus diperbaiki ataupun yang harus di hilangkan sehingga dapat menajamkan strategi untuk menghadapi sebuah persaingan dalam bisnis.

\section{METODE PERANCANGAN}

Perancangan sistem informasi yang akan dipakai metode Unified Modeling Language (UML)yang akan dituangkan dalam usecase diagram dan class diagram dengan menggunakan alat bantu (tool) berupa visual paradigm for UML 6.4 enterprise edition.bahasa pemprograman yang digunakan yaitu PHP dengan framework YII Serta penjabaran rancangan basis data dan spesifikasinya menggunakan beberapa software yaitu XAMPP,MYSQL,Chrome. 


\section{LITERATURE REVIEW}

1. Penelitian yang dilakukan Phindile Ndlala and Charles Mbohwa,Kehinde Sobiyi.Proceedings of the 2017 International Symposium on Industrial Engineering and Operations Management (IEOM) Bristol, UK, July 24-25, 2017 978-1-5090-392 dengan judul "The Application Inventory Control Systems in Warehouse"kelebihan pengendalian persedian stock perlu dilakukan agar tidak terjadi kerugian dalam bentuk materi upaya peningkatan kontrol inventaris untuk menghasilkan produk dan layanan kepada pelanggan mereka dengan cepat dengan biaya rendah,kelemahaan pengendalian persediaan yang tidak efektif adalah masalah utama.

2. Penelitian yang dilakukan oleh Meta Amelya Dewi dan Rani Andriani ULTIMA InfoSys, Vol. VIII, No. 2 Desember 2017 ISSN 2085-4579 dengan judul "Implementasi Scrum Model Development Pada Monitoring Inventory Control Cleaning Equipment dan Chemical PT. Explore Global Solution". Adapun kesimpulan dari penelitian 1.Penerapan scrum model dapat menghasilkan aplikasi monitoring inventory control cleaning equipment dan chemical yang terdiri dari 6 backlog, 6 sprint, scrum meeting harian dan demo aplikasi yang sangat menunjang dalam perancangan aplikasi dengan waktu penyelesaian selama 373 jam atau disamakan dengan 5 hari kerja 8 jam perhari adalah 9 minggu 3 hari. kekurangan perlu dilakukan pengembangan sistem monitoring stock control sebagai kendali persediaan barang yang dapat mengatasi berbagai kendala dan permasalahan yang terjadi dengan memanfaatkan kemajuan teknologi yang ada, yaitu membangun aplikasi berbasis web yang dapat memberikan informasi yang dibutuhkan

3. Penelitian yang dilakukan oleh Ade Hendinijurnal khatulistiwa informatika, vol. IV, NO. 2 desember 2016 dengan judul "pemodelan UML sistem monitoring penjualan dan stok barang (studi kasus :distro zhezhe Pontianak"kelebihan Dengan adanya sistem informasi monitoring penjualan dan stok barang ini, mempermudah pelaku usaha dalam memantau atau mengetahui penjualan dan stok barang ditiap cabang dan Melalui sistem informasi monitoring penjualan dan stok barang ini dapat membantu pelaku usaha dalam menentukan keputusan dari informasi-informasi yang didapat dari tiap-tiap cabang adapun barang dan pengontrollan karyawan dalam hal presensi karyawan. Kekurangan 1.Sebaiknya sistem ini dikembangkan pula dalam hal pendistribusian barang dan pengontrollan karyawan dalam hal presensi karyawan.2. Pengembangan selanjutnya dapat diterapkan ke aplikasi berbasis smartphone, dalam rangka mempermudah pemilik usaha untuk mengakses data dan informasi. Metode penelitian yang dilakukan yaitu dengan melakukan analisis terhadap sistem yang sedang berjalan, mengidentifikasi kebutuhan. Adapun alat bantu yang digunakan adalah UML yang digunakan.

\section{Perancangan Sistem}

\section{HASIL DAN PEMBAHASAN}

Sistem yang dirancang dengan menggunakan alat bantu (tool) UML (unified Modelling Language) dengan diagram usecase : 


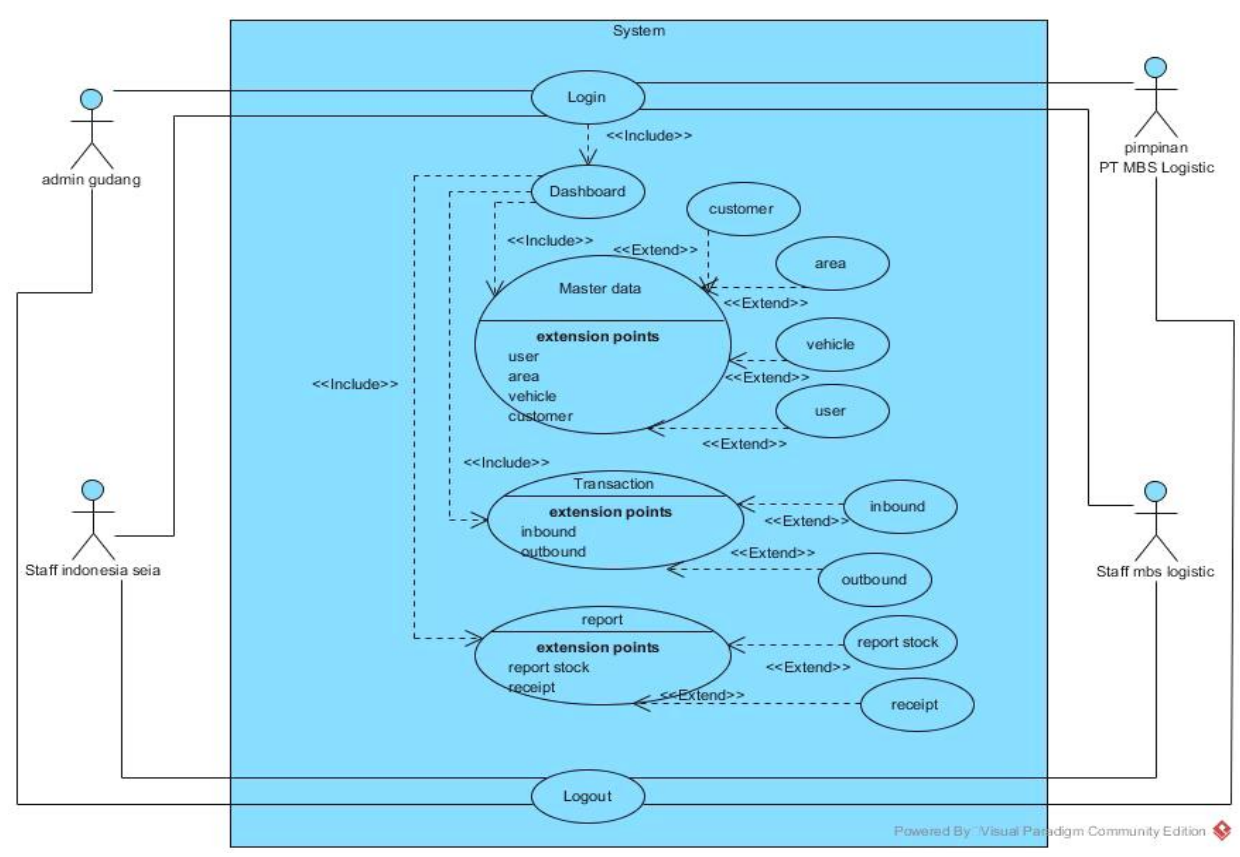

Gambar 1. Use Case Sistem Yang Diusulkan

1. Terdapat 4 aktor yaitu admin gudang,staff Indonesia seia,staff mbs logistic,pimpinan PT mbs logistic.

2. Terdapat 6 usecase yaitu.login,dashboard,master data,transection,report,

3. Terdapat 8 extends yaitu .custumer,area, vehicle, user,inbound,outbound, report stock, receipt

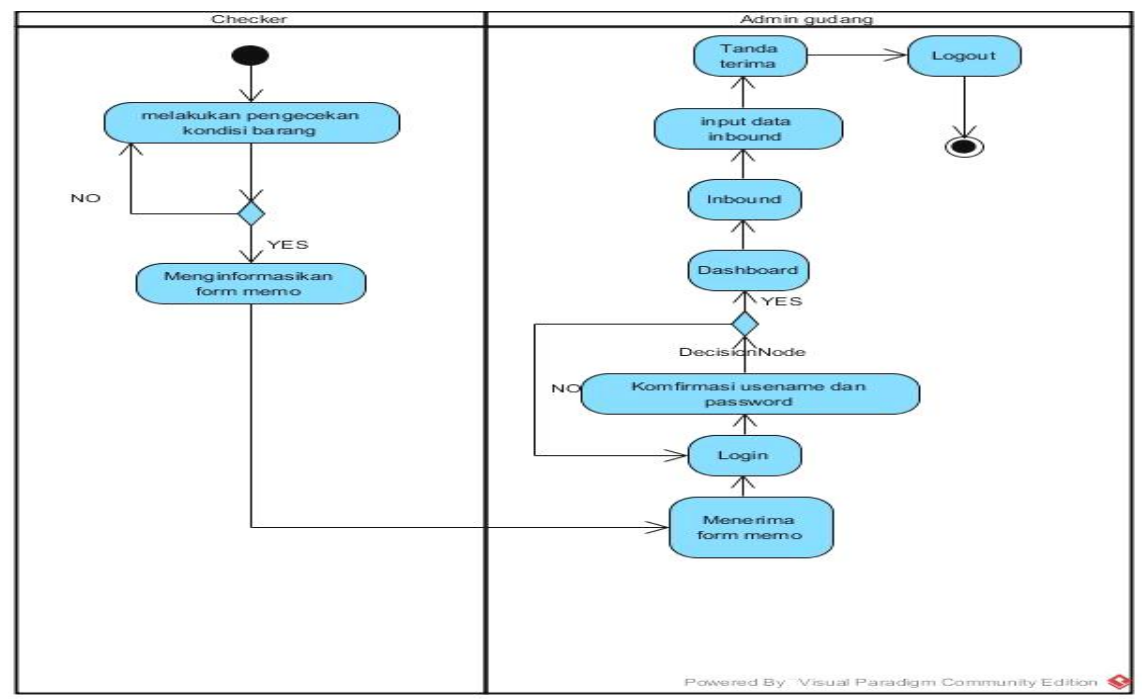

Gambar 2. Activity Diagram Inbound

a. 1 initial Node, objek yang diawali

b. 10 Action, dari sistem yang mencerminkan eksekusi dari suatu aksi.

c. 2 Decesion Node yang merupakan pemilihan ya atau tidak.

d. 1 Activity Final Node, objek yang diakhiri. 


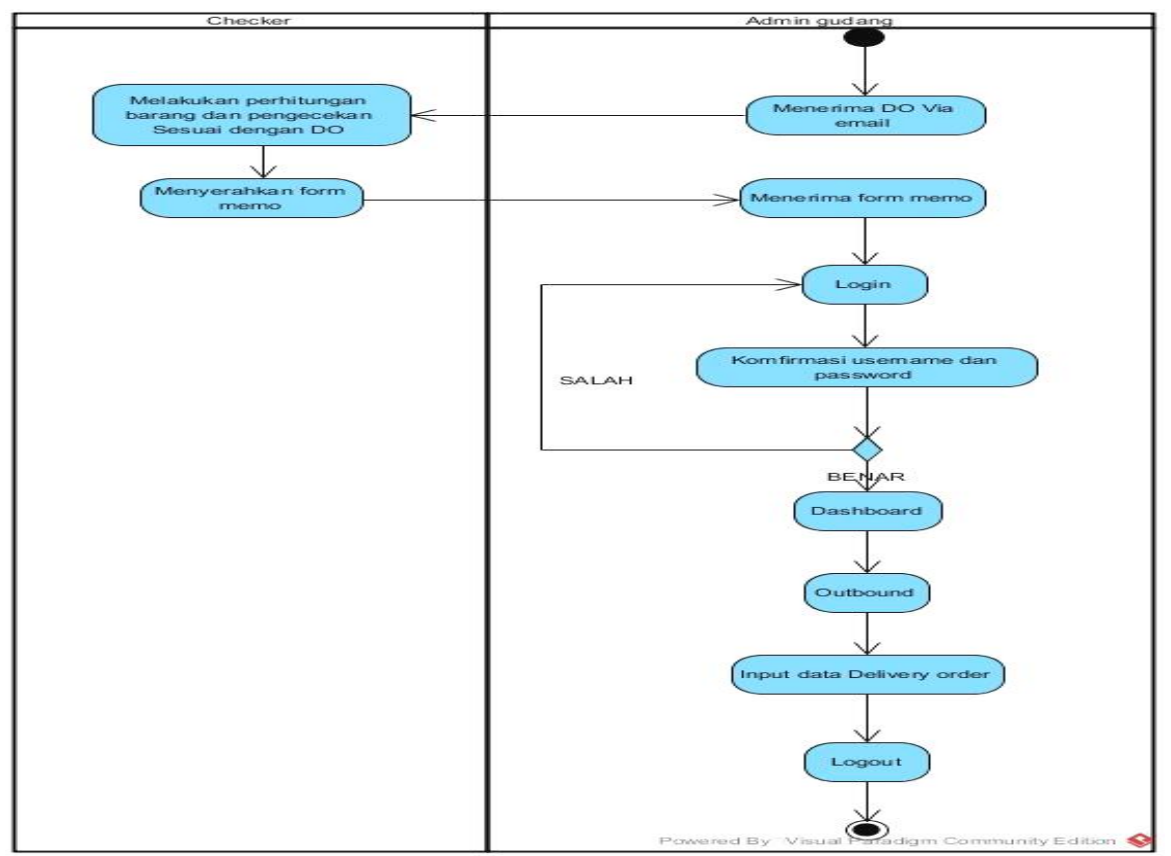

Gambar 3. Activity Diagram Outbound
a. 1 initial Node, objek yang diawali
b. 10Action, dari sistem yang mencerminkan eksekusi dari suatu aksi.
c. 1 Decesion Node yang merupakan pemilihan ya atau tidak.
d. 1 Activity Final Node, objek yang diakhiri.

\section{Perancangan Basis Data (Database)}

Perncangan basis data pada sistem informasi pemantahuan inventory stock opname berbasis web pada PT Makmur Berkat Solusi Logistic digambarkan dengan menggunakan pemodelan UML yaitu class diagram

Berikut adalah class diagram sistem tersebut :

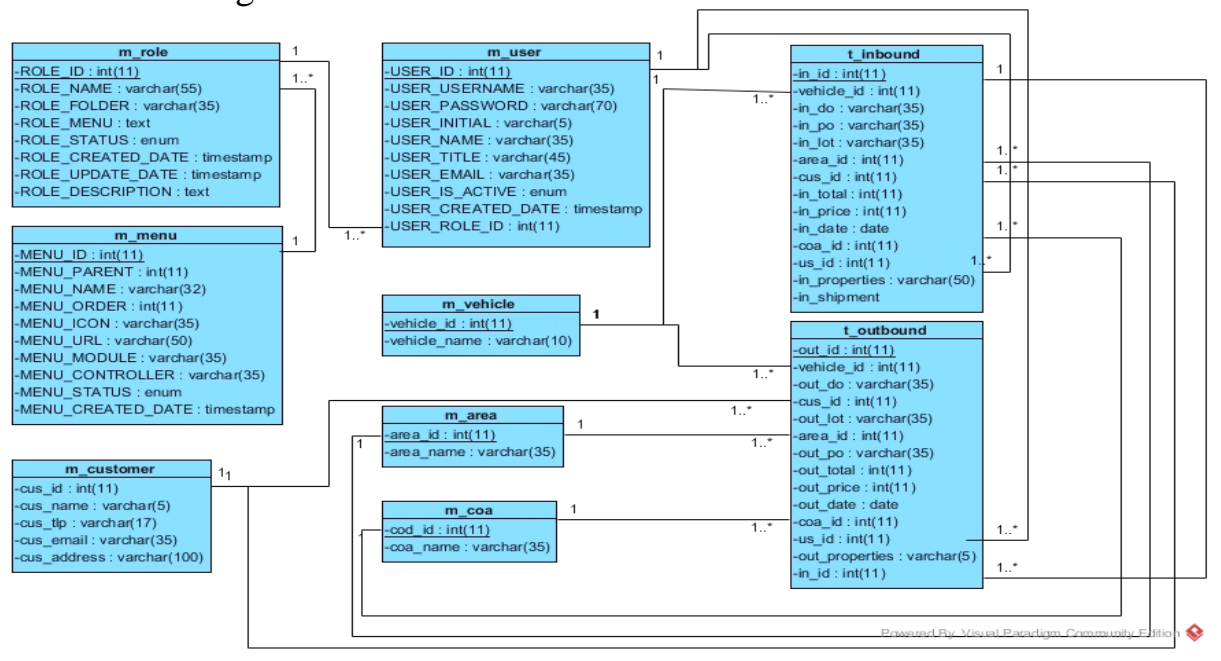

Gambar 4. Class Diagram 


\section{IMPLEMENTASI}

\section{Tampilan Halaman Login}

Setiap user wajib untuk login terlebih dahulu sebelum dapat mengakses sistem seperti gambar dibawah ini.

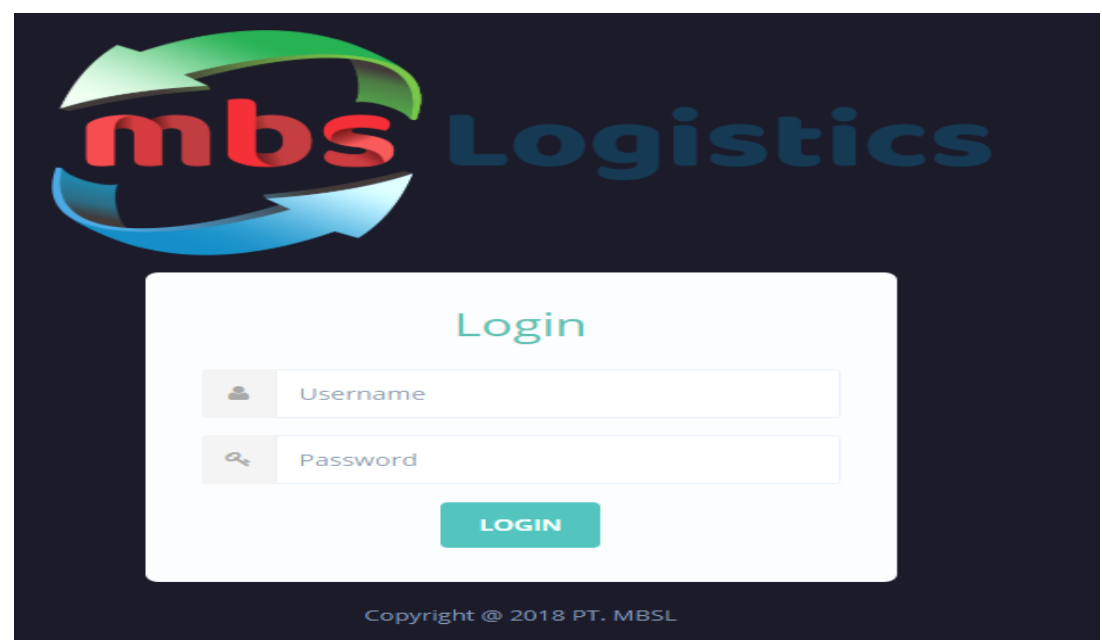

Gambar 5. Halaman Login

Keterangan : Tampilan halaman login sistem ini, setiap pengguna diwajibkan untuk login terlebih dahulu jika ingin mengakses sistem ini

\section{Tampilan menu utama}

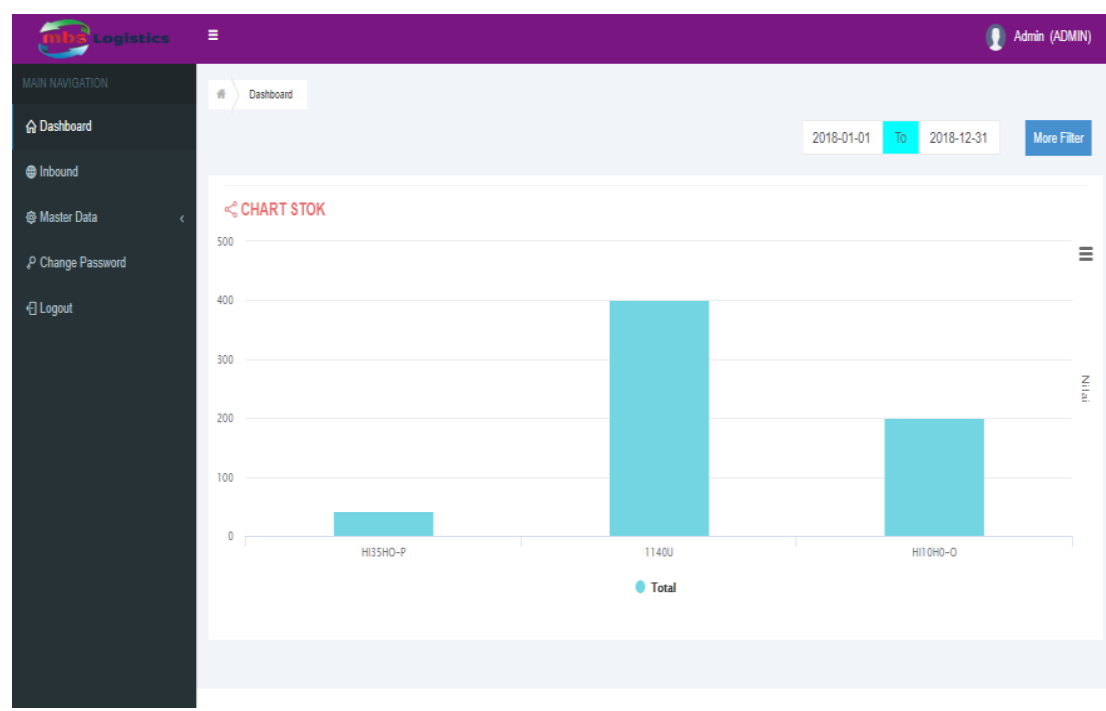

Gambar 6. Halaman menu Utama data master

Kerangan : Setelah berhasil login maka akan tampil halaman dashboard untuk tampilan grafik stock. 


\section{Tampilan Halaman Tambah Data Barang Inbound}

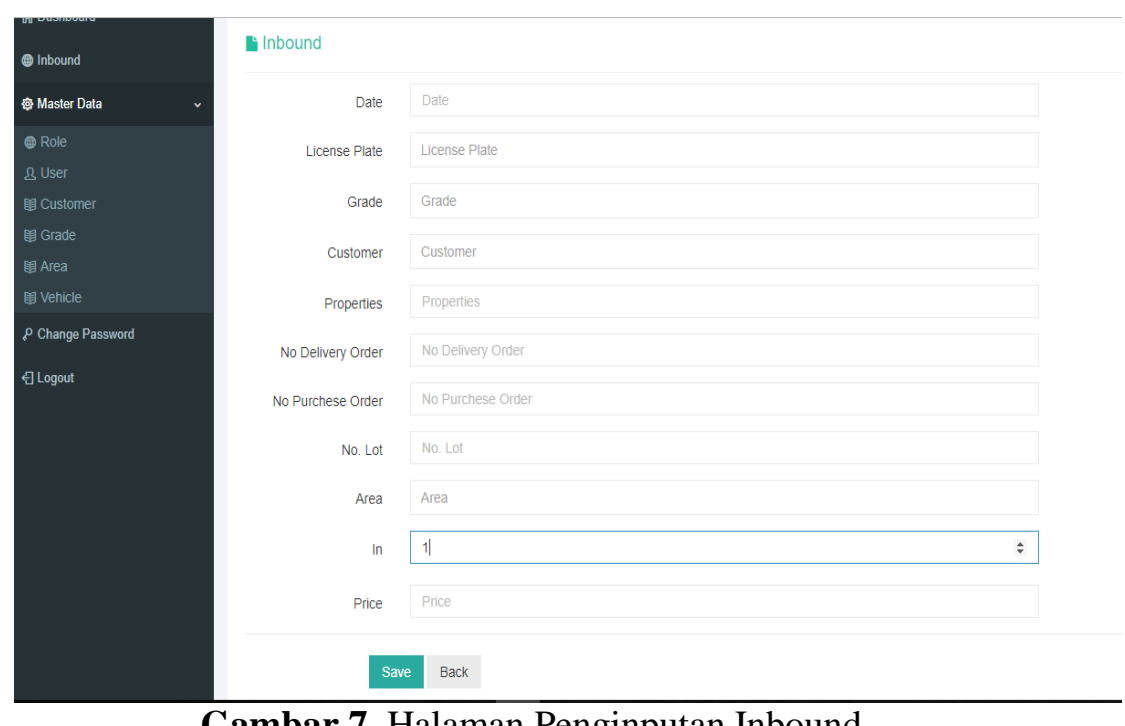

Gambar 7. Halaman Penginputan Inbound

Ketarangan : Berikut ini tampilan yang akan muncul jika admin akan menambah atau menginputan barang masuk.

\section{Tampilan Penginputan Data Outbound}

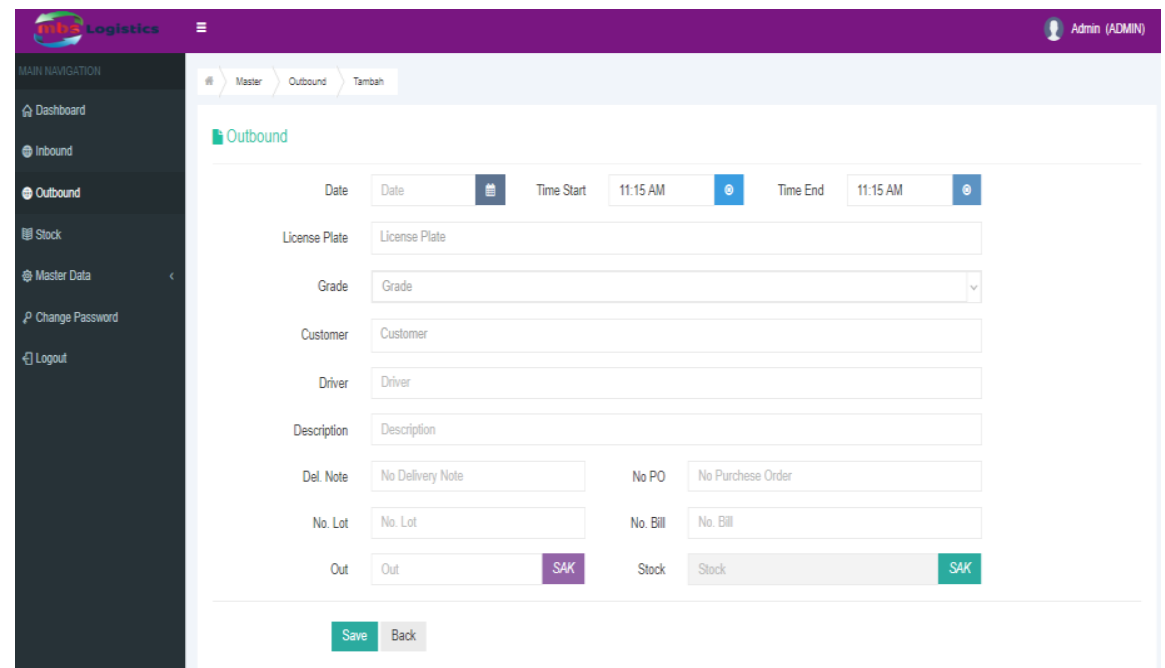

Gambar 8. Tampilan Halaman Penginputan data outbound

Ketarangan : Berikut ini tampilan yang akan muncul jika admin akan menambah atau menginputan barang keluar. 


\section{Tampilan Table Data Barang}

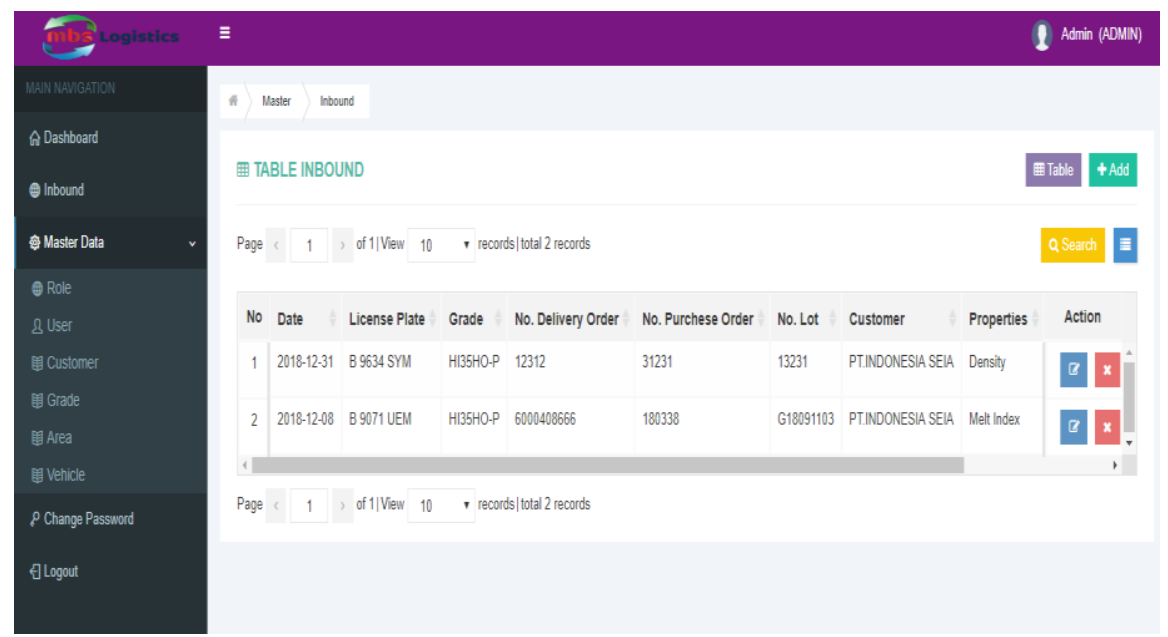

Gambar 9. Tampilan table data barang

Keterangan :Merupakan tampilan dimana daftar nama barang yang masuk pertanggal.

\section{Tampilan Laporan Dalam Bentuk PDF}

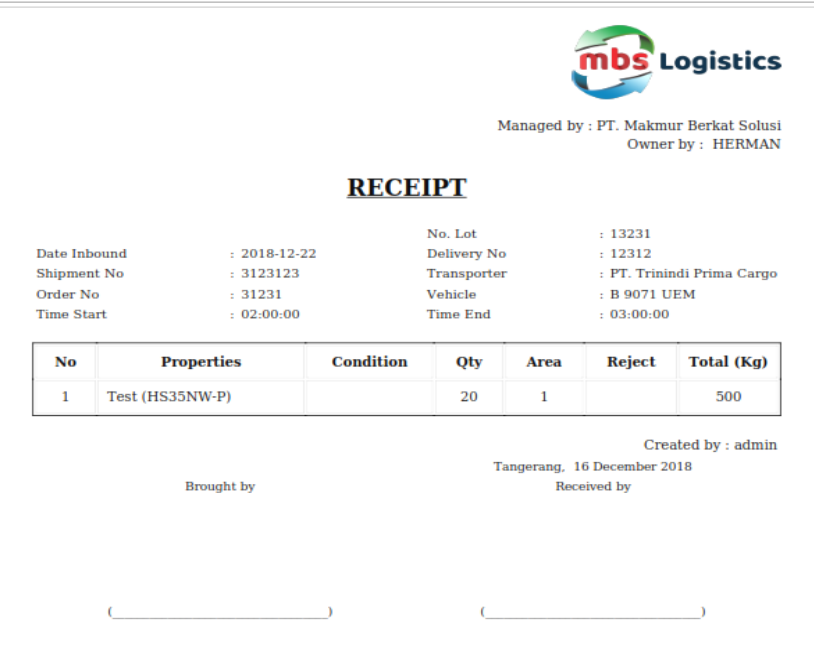

Gambar 10. Tampilan Laporan dalam bentuk PDF PDF

Ketarangan: Selesai membuat laporan berikut tampilan laporan di cetak dalam bentuk

\section{KESIMPULAN}

1. Merancang sistem yang bisa digunakan baik dalam pembuatan laporan yang mempermudah dalam melakukan perkerjaan dan tidak memakai waktu lama dalam pebuatan laporan Inbound dan Outbound.

2. Membantu dalam perancang sistem informasi yang bisa di pergunakan bagi perusahaan agar lebih baik lagi dalam pembuatan laporan penginputan data yang terjadi dan mempermudah proses dengan dibuat nya sistem yang baru. 


\section{DAFTAR PUSTAKA}

[1] Dewi, M. A., \& Andriani, R. (2017). Implementasi Scrum Model Development Pada Monitoring Inventory Control Cleaning Equipment dan Chemical PT. Explore Global Solution. Jurnal Ultima Infosys, 8(8), 112-117.

[2] Eman suherman 2015.praktek bisnis berbasis Entrepreneurship.Gramedia

[3] Dzulhaq,Iqbal,M,Rahmat tullah,Putra satia Nugraha.2017.Sistem Informasi Akademil Sekolah Berbasis Kurukulum 2013.jurnal sisfotek global Vol.7 no 1

[4] Hadi,Febri,Syafri Arlis,Sugeng Hariyanto.2017.Perancangan Aplikasi Pencarian Labor Dan Lokal Untuk Kuliah Pengganti DI universitas Putri Indonesia "Yptk"Padang.Jurnal Teknologi Vol.7,No.1.

[5] Hendini, A. (2016). Pemodelan Uml Sistem Informasi Monitoring Penjualan dan Stok Barang (Studi Kasus: Distro Zhezha Pontianak). Jurnal Khatulistiwa Informatika, 4(2).

[6] Noor,Muhammad,Ratna sari.2016.Sistem Informasi Kartu Inventaris Barang Berbasis Web Di Pertambangan Dan Energi Kabupaten Tanah laut.Jurnal Sains Dan Informatika Vol 2 No 1.

[7] Ndlala, P., Mbohwa, C., \& Sobiyi, K. (2017). The application inventory control systems in warehouse.

[8] Rosyidhana,Akbar.2014. Sistem Informasi Inventory dan Penjualan Berbasis Wev di took Bangunan Enggal Jaya Klaten.Tugas Akhir.Yogyakarta:Universitas Gadjah Mada.

[9] Santoso,Budi.2017.Perancangan Aplikasi Olap (Online Analitycal Processing)Penjualan Buku Pada Toko Buku Gramedia Lubuklinggau Dengan Metode Clustering.Jurnal Teknologi Informasi Mura Vol 9 No.2. 